\title{
SEJARAH PERJUANGAN JENDERAL SOEDIRMAN DALAM MEMPERTAHANKAN INDONESIA (1945-1950)
}

\author{
Agus Susilo \\ Dosen Pendidikan Sejarah STKIP PGRI Lubuklinggau \\ Email: Agussusilo594@yahoo.co.id
}

\begin{abstract}
Abstrak
Proklamasi kemerdekaan Indonesia yang diumumkan pada tanggal 17 Agustus 1945, memberikan semangat para pemimpin dan bangsa Indonesia seluruhnya untuk mulai berjuang keras untuk mempertahankan kemerdekaan itu. Jenderal Besar Soedirman merupakan pahlawan yang pernah berjuang untuk merebut kemerdekaan Republik Indonesia dari tangan penjajahan. Jenderal Soedirman berjuang memperjuangkan kemerdekaannya Indonesia dengan segala kekurangan keadaan pasukan dan melemahnya kesehatannya, namun rasa cinta terhadap bangsa Indonesia yang merdeka memicu semangatnya untuk tetap berjuang dalam keadaan apapun. Selain sebagai tokoh perjuangan yang handal beliau juga merupakan sosok yang Islami dari Muhammadiyah dan juga seorang guru teladan yang baik dan amanah. Dalam lingkungan militer, Jenderal Soedirman merupakan sosok yang mampu menjadi pendingin dan pemberi semangat dalam kegentingan pasukannya dari ancaman bangsa Barat. Soedirman merupakan salah satu pejuang dan pemimpin teladan bangsa ini. Pribadinya teguh pada prinsip dan keyakinan, selalu mengedepankan kepentingan masyarakat banyak dan bangsa di_atas kepentingan pribadinya. Dalam sejarah perjuangan Republik Indonesia, ia dicatat sebagai Panglima dan Jendral RI yang pertama dan termuda.
\end{abstract}

Kata Kunci: perjuangan, Jenderal Soedirman, Indonesia

\begin{abstract}
The proclamation of Indonesian independence announced on August 17, 1945, gave the spirit of Indonesian leaders and nations altogether to begin to fight hard to defend that independence. General Soedirman was a hero who had fought for the independence of the Republic of Indonesia from the hands of the colonials. General Soedirman struggled to fight for his independence in Indonesia with all the shortcomings of troops and the weakening of his health, but the love of an independent Indonesian nation sparked his zeal to keep fighting under any circumstances. In addition to being a reliable figure of struggle he is also an Islamic figure of Muhammadiyah and also a good model teacher and trustee. In the military environment, General Sudirman is a figure capable of being cooling and encouraging in the crunch of his troops from the threat of Western nations. Soedirman is one of the nation's leaders and leaders. His personality is firm on principles and beliefs, always putting the interests of many peoples and nations above his personal interests. In the history of the struggle of the Republic of Indonesia, he was recorded as Commander and General of the Republic of Indonesia first and youngest.
\end{abstract}

Keywords: struggle, General Soedirman, Indonesia

\section{PENDAHULUAN}

Pengaruh kolonialisme bangsa asing terutama Belanda telah masuk ke Indonesia sejak abad ke-16 sampai awal abad ke-20 yang membawa banyak pengaruh dalam perubahan dan pembentukan stratifikasi sosial masyarakat Indonesia, yang semula lebih ditentukan oleh kriteria pemilikan tanah pertanian dan kedudukan untuk mempertahankan kekuasaannya. Namun stratifikasi sosial pada masa pemerintahan kolonial Belanda yang terjadi pada masyarakat Indonesia berubah berdasarkan diskriminasi rasial 
sehingga terbentuklah tiga lapisan sosial dalam masyarakat yang tercantum dalam Regirings Reglement tahun 1854 (Irwanto, Dedi, 2007: 2).

Kedudukan negara Indonesia di_waktu zaman Belandamembuat bangsa Indonesia lebih menderita oleh juga dalam lingkungan pemerintahan negeri sendiri ia tidak berkuasa. Pemerintah biasa di_negeri Belanda menjadi Pemerintahan Tinggi untuk Indonesia dan dalam pemerintahannya pemerintah kolonial Belanda di_sini juga bangsa Belanda yang berkuasa: Gubernur Jenderal yang melakukan pemerintahan seorang diri saja, harus orang Belanda; dari Direktur departemen-departemen hanya 1 dan 8 yang bangsa Indonesia, juga pangkat tinggi yang lain kebanyakan dalam tangan bangsa Belanda (Pringgodigdo, A.K, 1991: 222).

Perjuangan untuk memperoleh kemerdekaan Indonesia merupakan rangkaian perjuangan yang panjang dan didukung oleh seluruh lapisan masyarakat baik yang berdasarkan nasionalisme maupun semangat keagamaan. Sebelum proklamasi kemerdekaan Indonesia dibacakan, Indonesia berada dalam penjajahan Jepang. Pada masa pemerintahan Jepang aktivitas baik bersifat formal maupun non formal berada di_bawah pengawasan Jepang. Selain itu terjadi kekerasan yang semena-mena terhadap rakyat Indonesia. Melihat kondisi seperti itu, semangat pemberontakan dan bergerilya sudah meluap-luap di_lapisan masyarakat Indonesia, karena sudah tidak tahan lagi menderita atas penindasan yang sudah melebihi batas-batas perikemanusiaan (Khamidah, 2008: 1).

Seseorang yang mempunyai bobot kepemimpinan yang cukup besar yang tersimpan dalam jiwanya. Tetapi, karena tidak terdapat situasi dan kondisi yang memungkinkan untuk berkembang, maka kepemimpinan itu hampir-hampir tidak kelihatan, atau hanya tampak dalam bobot yang kecil. Sebaliknya, seseorang yang memiliki bobot kepemimpinan dalam ukuran sedang, dapat saja muncul menjadi tokoh yang menonjol disebabkan oleh tersedianya situasi dan kondisi yang memungkinkan untuk mengembangkan kepemimpinan tersebut.

Berdasarkan latar belakang diatas, maka tujuan penelitian ini adalah sebagai berikut:

1. Untuk mengetahui perjuangan Indonesia Tahun 1945-1950

2. Untuk mengetahui kepemimpinan Jenderal Soedirman

3. Untuk mengetahui perjuangan Jenderal Soedirman Dalam Mempertahankan Indonesia 1945 1950

Masalah yang sering dihadapi oleh negara yang baru merdeka ialah pertentangan di_dalam, yakni pertentangan antara kekuatan-kekuatan 
yang ingin memaksakan agar bagian terbesar dari keinginannya diterima oleh pihak lain. Situasi seperti itu ditemukan pula dalam periode Perang Kemerdekaan Indonesia, khusus bagi Soedirman, situasi yang dihadapi ialah suasana pertentangan yang ditimbulkan oleh adanya perbedaan strategi antara pihak militer dan pihak politisi dalam memenangkan perjuangan secara umum dan perang secara khusus. Selain itu, ia juga menghadapi situasi lain yang disebabkan oleh usaha golongan politik tertentu untuk menempatkan angkatan perang di_bawah kekuasaan golongannya atau sekurang-kurangnya bersimpati kepada golongannya (Senakatha, 2016: 42).

Perjuangan bangsa Indonesia memiliki arti penting bagi kemerdekaan Indonesia. Republik Indonesia memproklamasikan kemerdekaannya pada tanggal 17 Agustus 1945, sejak saat itu Indonesia menjadi sebuah negara yang merdeka dan berdaulat. Kedaulatan Indonesia menjadi sebuah negara tetap tidak diakui oleh Belanda. Proklamasi kemerdekaan Indonesia bagi Belanda merupakan suatu pemberontakan. Sikap Belanda tersebut dikarenakan kemerdekaan Indonesia hanya sebuah gerakan yang dibuat oleh para pemimpin Indonesia yang bekerjasama dengan Jepang. Sehingga bagi Belanda, kemerdekaan Indonesia belum sepenuhnya mendapat dukungan dari rakyat Indonesia dan kedaulatan Indonesia masih berada di_tangan Belanda (Poesponegoro, Marwati Djoened \& Notosusanto, Nugroho, 2008: 8-9).

Menurut Dwi Purwoko dalam (Khamidah, 2008: 4), pada awal kedudukan Jepang di_Indonesia, Soedirman yang memiliki bakat sebagai pengajar berusaha mendapatkan izin dari pemerintah Jepang untuk membuka kembali Sekolah Muhammadiyah yang pernah ditutup oleh Belanda. Usahanya berhasil setelah mengalami berbagai kesulitan. Beberapa bulan kemudian, dia meninggalkan profesi sebagai guru dan mengikuti latihan militer pada saat Jepang membentuk Tentara Pembela Tanah Air (PETA). Setelah mengikuti latihan, dia diangkat menjadi Daidancho (Komandan Batalion PETA) di Banyumas. Perhatiannya terhadap kesejahteraan para prajurit sangat besar.

Sebagai tokoh masyarakat yang berasal dari Muhammadiyah, kemudian dilanjutkan dan diaplikasikan di_lingkungan angkatan perang, Soedirman dikenal sebagai pemimpin yang saleh, jujur, sederhana dan santun terhadap sesama. Dia pemimpin yang demokratis, arif dan bijaksana. Dia juga adalah seorang pemimpin yang istiqomah dan menganut doktrin amar maruf nahi munkar, bersikap tegas, pantang menyerah terhadap musuh, dan selalu memperjuangkan kepentingan masyarakat. Di samping itu dia konsisten 
dalam ajaran Islam meskipun dalam peperangan. Posisi Jenderal Soedirman sebagai peletak pertama fondasi ketentaraan sudah tampak tertancap kuat pada alam bawah sadar kolektif bangsa Indonesia.

\section{METODE PENELITIAN}

Penelitian sejarah akan memperoleh manfaat maksimal, apabila digunakan untuk tujuan menjawab hipotesis penelitian yang diajukan peneliti dan merekontruksi kembali peristiwa dan kehidupan masa lampau dengan tepat dan objektif, melalui usaha peneliti untuk merelokasi, mengevaluasi, dan menginterpretasi data tentang masa lampau. (Sukardi. 2003: 203-204). Langkah-langkahpenelitian sejarah adalah sebagai berikut:

\section{Heuristik}

Langkah awal dalam penelitian sejarah adalah heuristik. Heuristik berasal dari bahasa Yunani hueriskan yang artinya memperoleh. Heuristik adalah teknik atau cara-cara untuk menemukan sumber yang bisa didapat melalui studi kepustakaan, pengamatan secara langsung di_lapangan atau melalui interview (Alian, 2012: 9-10).

Penelitian berusaha mencari dan mengumpulkan sumber yang berhubungan dengan permasalahan di_atas, adapun sumber yang penulis dapatkan diantaranya dari Perpustakaan STKIP PGRI Lubuklinggau, Perpustakaan Prodi Sejarah STKIP PGRI Lubuklinggau, Toko Buku di Palembang. Buku-buku dan sumber lainnya tersebut diperoleh melalui studi kepustakaan (library research). Karena perpustakaan merupakan laboratorium pada sejarawan (Gottschalk, 1986: 86).

\section{Kritik Sumber}

Dalam menggunakan sumber-sumber sejarah, haruslah mengevaluasi atau melakukan kritik terhadap sumbersumber yang digunakan. Kritik sumber adalah proses menguji sumber, apakah sumber yang dikemukakan asli atau palsu (kritik ekstern) dan apakah dapat dipercaya atau dipertanggung jawabkan atau tidak (Alian, 2012: 11).

Kritik ada dua macam, yaitu: Kritik Ekstern dan Kritik Intern. Kritik ekstern adalah menyelidiki untuk menentukan keaslian dengan menjawab pertanyaan-pertanyaan $5 \mathrm{~W}+1 \mathrm{H}$. Sedangkan kritik intern adalah penentuan dapat tidaknya keterangan dalam dokumen digunakan sebagai fakta sejarah (Yass, 2004: 35-36).

\section{Kritik Ekstern}

Menurut Kamus Besar Bahasa Indonesia Edisi Keempat (Depdiknas, 2008: 742), kritik ekstern adalah tahap penelitian yang berdasarkan liputan fisik berupa deskripsi bentuk, jenis aksara, bahan, 
lingkungan, dan lingkungan, lokasi keberadaan prasasti. Bila sumber tersebut merupakan sumber tertulis seperti buku, maka peneliti harus melihat hal-hal yang berkaitan dengan penampilan luar yang meliputi kertas, tintanya tulisan kalimat, gaya bahasa/ejaan yang digunakan pengarang (Kuntowijoyo, 1995: 99).

\section{Kritik Intern}

Menurut Kamus Besar Bahasa Indonesia Edisi Keempat (Depdiknas, 2008: 742), kritik intern adalah tahap kerja yang dilakukan berdasarkan hasil liputan data lapangan yang membangun baik sumber tertulis maupun analogi epigraf.Kritik intern adalah suatu usaha analisis untuk menjawab pertanyaan yang menyangkut akurasi, nilai dokumen, dan autentisitas peninggalan yang telah diperoleh dari lapangan (Sukardi, 2003: 206).

\section{Interpretasi}

Langkah ketiga dalam penelitian sejarah adalah Interpretasi. Interpretasi diperlukan agar data yang mati dapat berbicara atau mempunyai arti. Interpretasi ada dua macam, yaitu analisis dan sintesis (Kuntowijoyo, 1994: 100).

\section{Historiografi}

Setelah dilakukan proses heuristik, interpretasi, dan kritis sumber sebagai tahap akhir dalam metode sejarah adalah teknik penulisan atau dikenal dengan historiografi. Historiografi adalah rekonstruksi yang imajinatif dari masa lampau berdasarkan data yang diperoleh dengan menempuh proses (Gootschalk, 1986: 32).

Penulisan laporan disusun berdasarkan serialisasi (kronologis, kausasi, dan imajinasi). Penulisan sejarah sedapat mungkin disusun berdasarkan kronologis, ini sangat penting agar peristiwa sejarah tidak terlalu penting dan cenderung dikerjakan berdasarkan dikerjakan berdasarkan sistematika (Kuntowijoyo, 1995: 103).

\section{HASIL DAN PEMBAHASAN}

Perjuangan Indonesia Tahun 1945-1950 Besarnya kekuasaan bangsa Belanda terhadap Indonesia, baik dari segi kehidupan golongan Indonesia saja, namun juga terhadap kehidupan dari negeri Belanda maupun Indonesia sendiri, semua lapangan hidup di_Indonesia menunjukkan kepincangan yang bukan terlihat terhadap negeri seumurannya. Tidak mengherankan, bahwa dengan keadaan yang tergambar, rakyat Indonesia sama sekali tidak tenang. Semua orang tahu bahwa bahwa kunci perbaikan yang betul-betul, membuat segala lapangan, terletak pada kedudukan dalam pemerintahan, pada kekuasaan mengatur negeri, pada "kuasa politik". Oleh sebab itu, membuat orang Indonesia selalu hal pemerintahan, hal politiklah yang diutamakan (Pringgodigdo, A.K, 1991: 223-224). 
Pendidikan yang dijalankan oleh Pemerintahan Hindia Belanda pada dasarnya untuk menjadikan warga negara yang mengabdi kepada kepentingan penjajah, dengan kata lain pendidikan dimaksudkan untuk mencetak tenagatenaga yang dapat digunakan sebagai alat untuk memperkuat kedudukan penjajah, mengabdi kepada kepentingan bangsa Belanda. Oleh karena itu, tujuan pendidikan diarahkan kepada kepentingan kolonial, maka si pendidikanpun hanya sekedar pengetahuan dan kecakapan yang dapat membantu mempertahankan kekuasaan politik ekonomi jajahan. Belanda tidak ingin merugi atas segala kebijakan yang telah diterapkannya terhadap kaum pribumi. Tetapi sifat pendidikan seperti itu, mulai awal abad ke-20, berangsurangsur berubah. Hal ini disebabkan politik etis (ethische polity) sebagai bentuk politik balas budi pemerintah Hindia Belanda terhadap kaum pribumi (Irwanto, Dedi, 2007: 3-4).

Pada tanggal 29 September 1945 tentara Sekutu yang ditugaskan untuk menduduki wilayah Indonesia dan melucuti tentara-tentara Jepang tiba di Jakarta. Pelaksana tugas ini adalah Komando Asia Tenggara (South East Asia Command) di_bawah pimpinan Laksamana Lord Louis Mountbatten. Untuk melaksanakan tugas itu, Mountbatten membentuk suatu komando khusus yang diberi nama Allied Forces
Netherlands East Indies (AFNEI) di_bawah Lentan Jenderal Sir Philip Christison. Tugas dari komando ini adalah menerima kekuasaan dari tangan Jepang, membebaskan tawanan perang dan interniran Sekutu, serta melucuti dan mengumpulkan orang Jepang kemudian dipulangkan. Kedatangan Sekutu semula disambut dengan tangan terbuka. Namun ketika diketahui bahwa pasukan Sekutu diboncengi oleh Netherlands Indies Civil Administration atau Pemerintahan Sipil Belanda (NICA) yang akan menguasai wilayah Indonesia, sikap Indonesia mulai curiga dan waspada. Berbagai upaya, bangsa Indonesia tetap mempertahankan kemerdekaan rakyat Indonesia bangkit melawan tentara Sekutu dan NICA. Akibatnya berkobarlah pertempuran di_berbagai daerah di_Indonesia antara lain adalah Medan, Palembang, Bandung, Semarang, Ambarawa, Surabaya, Makasar dan Bali.

Dari delapan kota tersebut, Ambarawa merupakan kota yang paling kecil. Namun keberadaan kota ini memang sangat strategis. Ambarawa merupakan jalur utama yang menghubungkan antara Semarang, Mangelang menuju Yogyakarta. Meskipun kota kecil, namun para pejuang di Ambarawa mampu mengusir Sekutu terutama Inggris mundur ke Semarang. Ambarawa sebagai kota kecil, mampu 
mempertahankan kemerdekaan dari tangan penjajah (Moehkardi, 2008: 118).

Kemenangan yang diperoleh Tentara Keamanan Rakyat (TKR) dan pasukan Rakyat di Ambarawa cukup menengangkan dunia luar. Propaganda yang dilaksanakan oleh Sekutu terutama Belanda mengatakan bahwa apa yang dinamakan Tentara Keamanan Rakyat adalah tidak lebih dari segerombolan pengacau yang ekstrimis ternyata berbeda. Palagan Ambarawa merupakan suatu bukti pagaleran militer yang teratur dari sebuah taktik pertempuran yang diterapkan oleh pimpinan yang terampil. Namun di_sisi lain pihak Belanda tampaknya tetap meremehkannya karena mereka merasa perwira-perwira yang sudah berpengalaman dalam Perang Dunia kedua (Tjokropranolo, 1992: 57).

Kemenangan yang diperoleh Ambarawa tidak lepas dari tokoh yang bernama Jenderal Soedirman. Sosok yang sangat ringkih, kurus, lemah dan sama sekali tidak tampakmenampakan keperkasaan fisiknya. $\mathrm{Di}$ sisi lain Soedirman mempunyai sifat peduli terhadap pendidikan, nasionalisme, keislaman, dan bakat dalam hal militer. Soedirman juga dikenal sebagai orang yang pantang menyerah, berwatak keras untuk menegakkan prinsip. Kehadirannya di_dunia militer mampu memberi motivasi yang tinggi bagi pasukan Indonesia yang berjuang mempertahankan kemerdekaan (Kholid, O. Santoso, 2007: 177-178).

\section{KepemimpinanKepemimpinana Jenderal Soedirman}

Jenderal Soedirman dikenal sebagai guru yang tertib, disiplin, dan bertanggung jawab. Mengingat prestasi, penampilan, wawasan, dan kepemimpinannya, maka Soedirman dipilih sebagai Kepala Sekolah di_HIS Muhammadiyah. Soedirman menjadi Kepala Sekolah yang moderat, demokratis, dan akomodatif. Inilah Soedirman sebagai guru yang teladan. Beliau selalu memegang prinsip kepemimpinannya yaitu ing ngarso sung tulandha, ing madya mangun karsa, dan tut wuri handayani. Artinya dari prinsip itu adalah "Di depan memberi contoh, di_tengah memberi semangat, di_belakang memberi doronangan" (Sardiman, 2008: 83).

Dalam kajian sejarah, kepemimpinan Jenderal Soedirman dan Letnan Jenderal Oerip Soemohardjo dalam memimpin perjuangan TKR membawa dampak yang positif bagi perkembangan dan pertumbuhan tentara nasional pada masa-masa awal. Dalam kondisi seperti inilah bakat kepemimpinan Jenderal Soedirman tampak efektif. Menghadapi tugas penertiban organisasi suatu tentara yang masih jauh dari profesionalisme maka nonprofesionalisme fleksibel dapat 
mengisi profesionalisme yang kuat pada diri Oerip Soemohardjo. Selain itu, usia Soedirman yang relatif muda (29 tahun) saat terpilih menjadi Panglima Besar, merupakan suatu aset dalam menghadapi para panglima bawahannya yang ratarata berusia muda dan bersikap emosional. Soedirman merupakan sosok yang bisa menenangkan dan menstabilkan mereka (Saleh, B.A, 2007: $11-12)$

Dalam catatan Nasution, Jenderal Soedirman terpilih karena TKR saat itu didominasi alumni Peta, selain unsur KNIL, Heiho, dan pemuda. Di kalangan Peta, terutama beberapa di Jawa, Soedirman sangat cukup dikenal. Dua hari setelah pemilihan Soedirman, tepatnya pada tanggal 14 November 1945, Perdana Menteri Sutan Sjahrir mengumumkan komposisi kabinet. Sjahrir menunjuk Amir Syarifuddin sebagai Menteri Pertahanan (Tempo, 2012: 11-12).

\section{Panglima Besar Jenderal \\ Sudirman merupakan sosok pejuang} sejati yang tidak mengenal menyerah untuk terus berjuang melawan kekuatan asing yang berusaha menguasai kembali bumi pertiwi. Pada saat pasukan Belanda kembali melakukan agresinya atau yang lebih dikenal dengan sebutan Agresi Militer II Belanda, Ibu kota Negara RI berada di Yogyakarta sebab Kota Jakarta sebelumnya sudah dikuasai. Walaupun dalam dalam kondisi sakit- sakitan karena menderita sakit paru-paru yang sangat parah, beliau tetap bergerilya memimpin pasukan melawan Agresi Militer II Belanda di Yogyakarta dengan penuh semangat dan dedikasi yang tinggi. Padahal Bung Karno dan Bung Hatta serta beberapa anggota kabinet juga sudah ditawan karena dalam Agresi Militer II Belanda itu, Yogyakarta pun kemudian berhasil dikuasai Belanda. Presiden Soekarno sebelumnya telah menganjurkannya untuk tetap tinggal dalam kota untuk melakukan perawatan. Namun anjuran itu tidak bisa dipenuhinya karena dorongan hatinya untuk melakukan perlawanan pada Belanda serta mengingat akan tanggungjawabnya sebagai pemimpin tentara.

Pengorbanan Panglima Besar Jenderal Sudirman dalam babak sejarah perjuangan bangsa Indonesia begitu sangat besar, sehingga sangatlah wajar apabila sosok yang mengantarkan bangsa ini meraih kemerdekaan dan kedaulatan dijadikan sebagai figur kepahlawanan nasional yang patut ditiru dan dicontoh oleh seluruh lapisan masyarakat. Melalui kajian Kepemimpinan Panglima Besar Jenderal Sudirman ini, diharapkan agar para pemimpin bangsa, generasi muda TNI khususnya maupun generasi muda bangsa Indonesia pada umumnya dapat meneladani dan mengembangkan semangat perjuangan Panglima Besar Jenderal Sudirman dalam membangun 
tatanan kehidupan berbangsa dan bernegara yang lebih baik dan maju (Kemhan RI, 2015: 18-19. ).

\section{Perjuangan Jenderal Soedirman Dalam} Mempertahankan Indonesia 19451950

Peristiwa proklamasi 17 Agustus 1945 bukanlah titik batas akhir perjuangan kemerdekaan Indonesia. Setiap bangsa yang merdeka tentunya terus berjuang untuk mengisi dan mempertahankan kemerdekaan, karena kemerdekaan yang diproklamasikan merupakan manifestasi politik dari kesiapan rakyat Indonesia untuk selangkah lebih maju melewati proses penyempurnaan arti dari kemerdekaan yang sesungguhnya. Proklamasi kemerdekaan Indonesia merupakan titik awal untuk bersamasama merasa sebagai satu bangsa dengan satu bahasa satu wilayah yang sama untuk membangun bangsa Indonesia (Yunani, 2004: 3).

Sejak dibentuknya Tentara Keamanan Rakyat, pada tanggal 5 Oktober 1945, Soekarno telah menunjuk Soeprijadi sebagai Menteri Keamanan Rakyat. Soedirman kemudian membuktikan, beliau pantas menjadi "Panglima di_antara Panglima”. Di Ambarawa, dengan pasukan yang praktis compang-camping, ia menghalau serdadu Belanda dan Sekutu yang merupakan tentara dengan persenjataan lengkap. Karena ia dipilih, bukan diangkat,
Soedirman menjunjung kewajiban moral untuk membuktikan kepada pemiliknya bahwa mereka tidak keliru. Adanya "mandat", Soedirman melangkah dan mengambil berbagai keputusan yang dikemudian hari menimbulkan perbantahan (Tempo: 2012: 137).

Ketika Revolusi kemerdekaan Indonesia meletus, Soedirman yang sedang berada di Jawa Barat bergegas untuk pulang ke Banyumas. Di daerah ini Soedirman mengambil langkah-langkah untuk menyusun organisasi Badan Keamanan Rakyat (BKR). Badan yang telah diumumkan pendiriannya oleh pemerintah tanggal 22 Agustus 1945 ini terdiri dari beberapa himpunan para alumni militer pada zaman Jepang, antara lain Peta, Heiho, Seinendan, Keibodan, Kaigun,dan Keisatsutai (Polisi). Pada tanggal 5 Oktober 1945, Soedirman menggabungkan satuansatuaan BKR di Banyumas menjadi satuan-satuan Tentara Keamanan Rakyat (TKR). Semua anggota TKR yang berada di Banyumas tersebut kemudian ditetapkan menjadi Divisi $\mathrm{V}$ Banyumas. Soedirman menjadi panglimanya dengan pangkat kolonel (Saleh, B.A, 2007: 6).

Saat Soedirman dalam keadaan sakit dan dalam perawatan di_rumahnya di Bintaran, Yogyakarta, situasi politik nasional semakin memanas. Pada bulan November 1948, hubungan antara Indonesia dengan Belanda semakin memburuk. Serangkaian usaha diplomasi 
berjalan tersendat-sendat. Belanda terus berusaha meningkatkan kekuatan bersenjatanya. Menghadapi perkembangan yang semakin memburuk itu, sekalipun dalam keadan sakit, Soedirman tetap melakukan koordinasi dengan para komandan agar semua kekuatan bersenjata selalu bersiaga (Sardiman, 2000: 195).

Pasukan Indonesia mendapat tugas dari Soedirman untuk menguasai jalan besar yang menghubungkan Ambarawa dan Semarang. Pada pukul 16.00 telah ada laporan bahwa mereka telah ada laporan bahwa mereka telah berhasil menguasai sasarannya. Setelah menerima laporan tersebut, Soedirman memerintahkan agar jalan besar yang telah dikuasai itu dipertahankan. Serangan umum yang dilancarkan pasukan TKR merupakan suatu gerakan pendobrak. Pasukan pemukul bergerak dari Barat ke arah Timur menuju Semarang. Sedangkan pasukan-pasukan yang bergerak dari arah samping kanan dan kiri merupakan suatu gerakan Supit Udang yang kedua ujungnya bertemu di_bagian luar kota Ambarawa.

Palagan Ambarawa telah memberikan dua makna besar dalam perjuangan bersenjata bangsa Indonesia setelah kemerdekaan. Adapun yang pertama adalah lahirnya seorang pemimpin militer sejati, yaitu Soedirman. Kedua adalah terbuktinya kepeloporan infantri. Oleh karena itu tanggal 15 Desember ditetapkan sebagai hari Infantri. Palagan Ambarawa merupakan kebangsaan bagi Korps Infantri yang dikenal dengan Thee Queen of Battlefield (Rudini, 1992: 448).

Demikian pengorbanan dan perjuangan seorang Panglima Besar Jenderal Soedirman yang tetap berjuang di_tengah-tengah anak buahnya dengan kondisi paru-paru yang tinggal sebelah ketimbang harus tinggal di_kota untuk berobat demi mempertahankan NKRI. Untuk mengenang dan menghargai jasa Jenderal Soedirman, pemerintah memberikan penghargaan tertinggi berupa gelar Pahlawan Nasional pada tanggal 20 Mei 1970. Menjelang memperingati hari Angkatan Bersenjata Republik Indonesia ke-52, pemerintah Republik Indonesia menganugerahi pangkat kehormatan Jenderal Besar TNI atau Jenderal Bintang Lima kepada Panglima Besar Jenderal Soedirman berdasarkan Keputusan Presiden Nomor 44/ABRI/1997 (Senakatha, 2016: 10).

\section{PENUTUP}

\section{Simpulan}

Proklamasi

kemerdekaan

Indonesia yang diumumkan pada tanggal 17 Agustus 1945, memberikan semangat para pemimpin dan bangsa Indonesia seluruhnya untuk mulai berjuang keras untuk mempertahankan kemerdekaan itu. Para pemuda terus bergerak menegakkan kemerdekaan, baik di_kota Jakarta, maupun di_daerah-daerah 
ditanah air. Pada perang mempertahankan kemerdekaan Indonesia, Jenderal Soedirman menjadi figur yang sangat penting dalam sejarah Republik Indonesia. Karakter kepemimpinan, sikap patriotisme, dan semangat bela negaranya, menyatu dalam jalannya sejarah revolusi Indonesia.

Jenderal Besar Soedirman merupakan pahlawan yang pernah berjuang untuk merebut kemerdekaan Republik Indonesia dari tangan penjajahan. Jenderal Soedirman berjuang memperjuangkan kemerdekaannya Indonesia dengan segala kekurangan keadaan pasukan dan melemahnya kesehatannya, namun rasa cinta terhadap bangsa Indonesia yang merdeka memicu semangatnya untuk tetap berjuang dalam keadaan apapun. Selain sebagai tokoh perjuangan yang handal beliau juga merupakan sosok yang Islami dari Muhammadiyah dan juga seorang guru teladan yang baik dan amanah. Dalam lingkungan militer, Jenderal Soedirman merupakan sosok yang mampu menjadi pendingin dan pemberi semangat dalam kegentingan pasukannya dari ancaman bangsa Barat. Jenderal Soedirman merupakan salah satu pejuang dan pemimpin teladan bangsa ini. Pribadinya teguh pada prinsip dan keyakinan, selalu mengedepankan kepentingan masyarakat banyak dan bangsa di_atas kepentingan pribadinya.

\section{Saran}

1. Peserta Didik

Belajar yang rajin, pantang menyerah dan terus berjuang untuk memperjuangkan masa depan bangsa. Terlebih lagi menghormati orang tua dan memperkuat tali silaturahmi antar sesama umat beragama.

2. Bagi Sekolah

Memperbanyak gambar pahlawan nasional merupakan langkah terbaik di_dalam lingkungan Sekolah dalam mengenalkan para pahlawan. Selain itu menyanyikan lagu-lagu Nasional sangat diperlukan untuk memperkokoh cinta tanah air dan bangsa bagi siswa dan lingkungan Sekolah.

3. Masyarakat Umum

Bagi masyarakat luas selalu mengajarkan pada generasi muda untuk selalu belajar yang rajin, mendidik anak yang baik dan selalu memantau anak dalam mengakses teknologi hasil arus globalisasi.

4. Pemerintah

Memperbanyak buku-buku referensi diberbagai perpustakaan-perpustaan lokal maupun nasional tentang bukubuku sejarah dan umum, serta menggalakan wajib membaca bagi masyarakat.

\section{DAFTAR PUSTAKA}


Alian, Sair. 2012. Metodologi Sejarah Dan Histiografi. Palembang: Proyek SP4

Depdiknas. 2008. Kamus Besar Bahasa Indonesia Pusat Bahasa Edisi Keempat.Jakarta: Gramedia Pustakan Utama.

Gottschalk, Louis. 1986. Mengerti Sejarah. Jakarta: Universitas Indonesia.

Irwanto, Dedi.2007. Sejarah Indonesia VI. Palembang: FKIP Sejarah Unsri.

Kemhan RI, 2015. Kepemimpinan Panglima Besar Jenderal Sudirman Saat Serangan Umum 1 Maret 1949 di Yogyakarta Dalam Mempertahankan Kemerdekaan Republik Indonesia. Bandung: Kemhan RI.

Khamidah, 2008. Perjuangan Jenderal Soedirman Pada Masa Revolusi Fisik (1945-1950).Yogyakarta: SKI UIN Sunan Kalijaga.

Kholid, O. Santoso, 2007: 177-178. JejakJejak Sang Pejuang Pemberontakan.Bandung: Sega Arsy.

Kuntowijoyo, 1995. Metodologi Sejarah. Yogyakarta: PT. Tiara Wacana.

Moehkardi, 2008. Pendidikan dan Pembentukan Perwira TNI-AD. Jakarta: PT.Inaltu.

Poesponegoro, Marwati Djoened \& Notosusanto, Nugroho, 2008. Sejarah Nasional Indonesia VI. Jakarta: Balai Pustaka.

Pringgodigdo, A.K, 1991. Sejarah Pergerakan Rakyat Indonesia. Jakarta: DianRakyat.

Rudini, 1992. Profil Provinsi Jawa Tengah. Jakarta: PT Intermasa.

Saleh, B.A, 2007: 11-12. Panglima Besar Jenderal Soedirman. Bandung: CV. Citra Praya

Sardiman, 2008. Panglima Besar Jenderal Sudirman Kader Muhammadiyah.Yogyakarta: Adi Cita Karya Nusa
Senakatha, 2016. Senakatha: Media Komunikasi dan Informasi Kesejarahan. Jakarta: Pusat Sejarah TNI.

Sukardi. 2003. Metodologi Penelitian Pendidikan. Jakarta: Bumi Aksara.

Tempo, 2012: 11-12. Soedirman: Seorang Panglima, Seorang Martir. Jakarta:KPG

Tjokropranolo, 1992. Panglima Besar Jenderal Soedirman Pemimpin Pendobrak Terakhir Penjajahan di_Indonesia. Jakarta: Surya Persindo.

Yass, Marzuki. 2004. Metodologi Sejarah Dan Histiografi. Palembang: Proyek SP4 Universitas Sriwijaya.

Yunani, 2004. Sejarah Nasional Indonesia V. Palembang: FKIP Sejarah Unsri. 